\title{
La (in)validez de los contratos celebrados por menores de edad en el código civil peruano
}

\author{
The (in)Validity of Contracts Celebrated by Minors \\ in the Peruvian Civil Code
}

\author{
Jhoel Chipana Catalán[*]
}

\begin{abstract}
RESUMEN: en este artículo se analiza la modificación del artículo 1359 del Código Civil, así como los cambios de las reglas sobre nulidad del acto jurídico, realizadas por la entrada en vigencia del Decreto Legislativo $\mathrm{N} .^{\circ} 1384$. El autor concluye que dicho cambio normativo ha sido perjudicial para el sistema jurídico peruano.

ABSTRACT: this article analyzes the modification of article 1359 of the Civil Code, as well as the changes to the rules about nullity in the legal act, made by the entry into force of Legislative Decree $N . \mathrm{o}$ 1384. The author concludes that this regulatory change has been harmful to the Peruvian legal system.
\end{abstract}

PALABRAS CLAVE: capacidad, discapacidad, discernimiento, nulidad, anulabilidad.

KEY WORDS: capacity, disability, discernment, nullity, revocability

\section{INTRODUCCIÓN}

La entrada en vigencia del Decreto Legislativo N. ${ }^{\circ} 1384$ ha traído una serie de cambios importantes en nuestro Código Civil, pues ha modificado varias instituciones (personas, acto jurídico, familia, contratos, responsabilidad civil y entre otros). Sin embargo, a un año de su entrada en vigencia (que se produjo en septiembre de 2018), aún no se logra entender muchas de esas modificaciones.

Confieso que, pese a la lectura y relectura de su contenido, no logro comprender cuál fue la finalidad de modificar el Código Civil de una manera tan poco reflexiva y sin ninguna orientación clara. Entiendo que la finalidad que se buscó fue la de

[*] Abogado por la Pontificia Universidad Católica del Perú, profesor de Derecho Civil y Arbitraje en la Universidad de San Martín de Porres, abogado consultor y árbitro. Es miembro fundador de Arbitration $360^{\circ}$. Correo electrónico: j.chipana@pucp.pe 
plasmar en un plano normativo muchas de las disposiciones contenidas en la Convención sobre los derechos de las personas con discapacidad (en adelante, CDPD), instrumento internacional del que nuestro país es parte signataria, pero dudo mucho que ese objetivo se haya logrado.

En este ensayo voy a emitir mi opinión sobre algunos de esos cambios que recayeron en la figura de la capacidad legal y cómo esta, al ser modifica$\mathrm{da}$, ha modificado diversos aspectos de la contratación civil. Específicamente, me referiré al contenido del artículo 1358 del Código Civil y su relación con la teoría de la nulidad del acto jurídico.

\section{EL ARTÍCULO 1358, EN SU TEXTO ORIGINAL}

El artículo 1358 del Código Civil tenía el siguiente texto:

Artículo 1358. «Los incapaces no privados de discernimiento pueden celebrar contratos relacionados con las necesidades ordinarias de su vida diaria».

Ya el propio Arias-Schreiber (2015) señaló en sus comentarios a este precepto la plena necesidad de esta regla, «cuya importancia práctica resulta indudable, habida cuenta de la pluralidad de situaciones en las cuales no se puede exigir que los incapaces no privados de discernimiento contraten por intermedio de sus representantes legales. Sería absurdo, por decir lo menos, que un menor de edad tenga que estar acompañado por su padre o su madre para ir de compras a cualquier establecimiento comercial. Si nos ciñéramos estrictamente a las reglas de la incapacidad sin un precepto como el comentado, esa adquisición sería nula, lo que ciertamente no se compadece con las prácticas de la vida cotidiana» (p. 43).

En efecto, la norma original del artículo 1358 reconocía una realidad, es decir, amparaba jurídicamente situaciones perfectamente razonables y necesarias para el desenvolvimiento de un incapaz con discernimiento.

Dicha norma estaba compuesta por elementos que, unidos en un todo, no hacían sino permitir la celebración de actos jurídicos válidos por personas a las que no se les debía negar el reconocimiento legal y la celebración de los mismos.
Así, se tiene que debíamos estar ante la presencia copulativa de los siguientes elementos:

- Un agente «incapaz»: aquí había que distinguir a las personas que caían en el supuesto de capacidad de ejercicio restringida de manera absoluta (incapaces absolutos) o capacidad de ejercicio restringida de manera relativa (incapaces relativos). La norma se enfocaba, principal pero no excluyentemente, en las personas menores de dieciséis años, en vista de que las personas que tenían entre dieciséis a dieciocho eran incapaces relativos, es decir, los actos que celebraban eran anulables. Entonces, el primer requisito para aplicar el artículo 1358 era el de un acto jurídico celebrado por un agente incapaz. Debo precisar que más adelante diferenciaré los términos «incapacidad» $y$ «discapacidad», pues la confusión sobre ambos ha servido como uno de los argumentos que se usaron para defender la modificación realizada en nuestro Código.

- Existencia de «discernimiento»: la norma utilizaba una fórmula negativa («no privados de discernimiento»), pero se entendía que debíamos estar ante una persona con discernimiento. Ello resultaba necesario, en vista de que el discernimiento es la posibilidad que tiene un agente de entender la realidad en la que se desenvuelve y poder diferenciar lo bueno de lo malo. La RAE señala que el término «discernir» significa «distinguir algo de otra cosa, señalando la diferencia que hay entre ellas». En el ámbito jurídico, se ha entendido siempre que esa posibilidad de distinguir obedece a lo que es favorable para los intereses de un sujeto, puesto que iría contra la razón celebrar un acto que tenga consecuencias negativas en la esfera de intereses de quien da su asentimiento para celebrar dicho acto. Así las cosas, para aplicar el artículo 1358 debíamos estar ante una persona con capacidad de ejercicio restringida (total o parcialmente), pero que tenga discernimiento. Cabe anotar que no existe consenso total en torno a la edad biológica que una persona debe tener para que se le impute un discernimiento pleno, pues todos 
aprehendemos a discernir en distintos momentos (se cree que entre los seis y ocho años es la edad en la que una persona tiene las aptitudes para discernir).

- Los contratos deben estar relacionados a las «necesidades ordinarias de su vida»: la construcción del contenido del artículo 1358 en su versión original debía tener una finalidad, pues no tenía sentido romper con la teoría de la nulidad por agente incapaz si es que no se ponderaba la consecución de un fin superior. Ese balance, que el legislador tuvo en mente al formular el artículo 1358, era muy razonable, pues la pregunta que surgía era si correspondía declarar nulos a todos los contratos que un agente incapaz con discernimiento celebraba, o es que debido a que esos actos servían para satisfacer necesidades ordinarias de su vida debían ser salvados de esa nulidad. La segunda alternativa se impuso, de tal suerte que el legislador, en un claro ánimo de conciliar la realidad con la norma jurídica, estableció esa excepción. Sin perjuicio de lo señalado, queda claro que conforme el tiempo ha transcurrido, la complejidad de muchos actos se ha ido incrementando, fundamentalmente debido a la contratación por medios electrónicos que hoy es moneda corriente. Piénsese en el supuesto de un menor con discernimiento que compra una laptop de US\$ 3 000, ¿acaso podríamos negar la validez de dicho contrato? Creo que no.

Teniendo en cuenta lo señalado, hasta septiembre de 2018, los menores con discernimiento podían celebrar, entre otros, los siguientes contratos: compraventa, prestación de servicios, comodato, permuta, donación.

Como se aprecia, esta norma era sabia y necesaria, pues habilitaba y reconocía la plena validez de millones de contratos que celebraban personas menores con discernimiento. Lamentablemente, el texto vigente ha desconocido esta realidad y, en su lugar, ha regulado un supuesto que flaco favor la hace a la idea de que el derecho debe ir de la mano con lo que ocurre en una sociedad, ya que hoy se puede afirmar que todos los contratos celebrados por menores con discernimiento son nulos.

\section{EL ARTÍCULO 1358, EN SU TEXTO VIGENTE}

El texto vigente del artículo 1358 del Código Civil establece lo siguiente:

Artículo 1358. «Contratos que puede celebrar la persona con capacidad de ejercicio restringida

Las personas con capacidad de ejercicio restringida contempladas en el artículo 44, numerales 4 al 8 , pueden celebrar contratos relacionados con las necesidades ordinarias de su vida diaria».

La norma hace referencia a los pródigos, los que incurren en mala gestión, los ebrios habituales, los toxicómanos, y los que sufren pena que lleva anexa la interdicción civil. Así, hoy la norma vigente señala que todas estas personas pueden celebrar contratos relacionados con las necesidades ordinarias de su vida diaria.

Aquí, la pregunta que surge es iacaso ello no era posible antes de que este artículo tenga el texto actual? Si analizamos la naturaleza de la incapacidad relativa en el régimen anterior (esto es, antes de la entrada en vigencia del Decreto Legislativo que lo ha modificado), podríamos llegar a la misma conclusión, en vista de que, al ser una incapacidad relativa, dichas personas solo estaban impedidas de celebrar los actos que el juez haya indicado en la sentencia por la que limitaba, en parte, la capacidad de ejercicio de dichos sujetos. Como es natural, ningún juez ordenaría que estas personas no puedan celebrar contratos que les permitan su propia subsistencia y desarrollo personal; sin embargo, al parecer el legislador que elaboró el Decreto Legislativo N. ${ }^{\circ} 1384$ no lo entendió así.

Así las cosas, las consecuencias que se otorga a los contratos celebrados por los cinco supuestos a los que la norma vigente hace referencia, eran posibles con la norma original, pues dichas personas antes de la entrada en vigencia del Decreto Legislativo sí podían celebrar contratos relacionados a las necesidades ordinarias de su vida. Si ello es así, ¿cuál fue la necesidad de que se haya modificado el artículo 1358 y se haya castigado con la nulidad a millones de contratos que los menores con discernimiento celebran para vivir? Creo que ninguna.

Sin duda, se aprecia una pésima técnica legislativa, un desconocimiento total de cómo es que la incapacidad relativa (o la hoy denominada capaci- 
dad de ejercicio restringida de manera relativa) funcionaba y cuáles eran los fines que ella perseguía. Me queda claro que la norma vigente contenida en el artículo 1358 no sirve de nada y la norma original era imprescindible para otorgar plena validez a actos que por su propia naturaleza exigen ser reconocidos y amparados por el sistema jurídico.

Entiendo que uno de los objetivos que se tuvo al modificar el Código Civil era implementar en un plano legislativo el contenido de la CDPD, pero en ese afán creo que se ha desnaturalizado una serie de figuras jurídicas que son absolutamente necesarias para resguardar, precisamente, los derechos de las personas con discapacidad.

En este punto, sí quiero dejar expresa constancia de que el contenido de la CDPD es valioso y necesario, a efectos de no discriminar a muchas personas que se han visto relegadas en una sociedad que no tiene las políticas públicas adecuadas para otorgarles la calidad de vida que merecen y el pleno reconocimiento de sus derechos. Lamentablemente, la forma en que esos fines se implementaron en el Código Civil ha sido simplemente desastrosa.

Solo por poner un ejemplo, hoy en día las personas con discapacidad que tengan un retardo mental grave son plenamente capaces ante la ley, lo cual importa que puedan celebrar contratos de distinta naturaleza. Antes, esos contratos eran nulos, porque la ley cautelaba los intereses de estas personas que no tenían discernimiento debido a esa discapacidad (retardo mental grave). Se aprecia que se ha metido en un solo supuesto todos los casos de problemas que atacan de manera directa al discernimiento y se ha logrado otorgar (de manera temeraria y muy peligrosa) el pleno ejercicio de derechos a estas personas, puesto que ahora la ley señala que son capaces.

Me temo que lo que va a ocurrir con esta modificación es que el Código Civil tiene doble filo, pues por un lado se está otorgando derechos plenos para que sean ejercidos por las personas que sí deben tenerlos (por ejemplo, personas con retardo mental leve), pero, por otro lado, se está permitiendo que un grupo de personas con discapacidad ejerzan sus derechos sin que puedan discernir sobre las consecuencias de sus actos y, peor aún, puedan ser inducidos a celebrar actos que vayan en contra de sus propios intereses.

Este es un tema que merece un análisis mayor, pero gracias a la entrada en vigencia del Decreto Legislativo $\mathrm{N}{ }^{\circ} 1384$ es claro que los incapaces con discernimiento celebran hoy en el Perú contratos que son nulos, lo cual resulta un sinsentido.

Por otro lado, debo recalcar que en ningún momento sostengo que la diversidad psíquica condicione la capacidad jurídica. Lo que señalo es que debemos separar conceptos y no caer en los errores del legislador que modificó el Código Civil usando como excusa la aplicación de la Convención a nuestra legislación.

De otro lado, en torno a la utilidad práctica del nuevo texto del artículo 1358 del Código Civil, se ha dicho que «frente a la práctica jurisprudencial peruana de no delimitar cabalmente el alcance de representación del curador al momento de su nombramiento en sede judicial, resulta conveniente una disposición normativa que precise, para los casos en los cuales aún se seguirá aplicando la curatela, que por más amplias que sean las facultades que se le confieran al curador, ello no significará (en ningún caso) una limitación en el ejercicio de sus derechos que conlleve la imposibilidad de que celebren contratos relacionados con las necesidades ordinarias de su vida diaria. Lógicamente, podría oponerse a lo apenas indicado que ello ya se encontraba regulado antes de la entrada en vigor del Decreto Legislativo $\mathrm{N} .{ }^{\circ} 1384$. Si bien, ello puede haber sido así, el hecho de la imprecisión en la delimitación jurisprudencial de las facultades del curador, así como el hecho de que se haya limitado el alcance de la curatela, al eliminarse la curatela de personas, justifica que se mantengan las precisiones necesarias para tratar de mantener la coherencia dentro del nuevo diseño legislativo» (Campos, s.f.).

Ante esta afirmación, solo debo mencionar tres cosas. La primera es que sería importante que se detalle cuál es esa «práctica jurisprudencial» que se invoca como argumento para otorgar sentido al actual artículo 1358 del Código Civil.

En segundo lugar, se acepta la tesis que sustento, pues lo que se dice es que el artículo 1358 ya se entendía así y se extraía de la lectura de las normas sobre capacidad e interdicción que teníamos, 
pero se sigue insistiendo en que el artículo actual es necesario para tener precisión y tratar de mantener coherencia. Yo me pregunto, ¿qué coherencia, si la regulación actual es un desastre?

Por último, y esto a modo de interrogante, ¿cuáles son las necesidades ordinarias de la vida de un toxicómano o un ebrio habitual a las que el artículo 1358 otorga hoy plena validez? ¿No son, entre otras, comprar drogas y alcohol? ¿A eso se refiere hoy el triste e innecesario artículo 1358? Es decir, ¿acaso esa norma le está otorgando validez a esos actos (junto a los que sirven, naturalmente, para la supervivencia de estas personas)? Como se aprecia, todo se ha entendido muy mal.

Lo reitero, el actual texto del artículo 1358 no aporta nada nuevo, pues lo que hoy quiere lograr ya se conseguía con la legislación anterior, en donde esas personas (me refiero a las que hace referencia el artículo 44, incisos 4 a 8), al encontrarse en la categoría de sujetos de derecho con capacidad relativa, sí podían contratar y celebrar los actos jurídicos que el juez no les había prohibido suscribir. Se ha cambiado una norma de gran valía, por una que nada nuevo dice y ningún aporte otorga.

\section{ALGUNOS APUNTES SOBRE LA PROTECCIÓN DE LAS PERSONAS CON DISCAPACIDAD}

Según el Censo Nacional del año 2017 (Instituto Nacional de Estadística e Informática, 2018), en el Perú existían más de tres millones y medio de peruanos cuya edad oscilaba entre los seis y quince años (tomo como referencia esas edades, debido a que seis años es la edad en la que se puede decir que una persona ya tiene discernimiento, y quince años porque es el límite de edad para no entrar al ámbito de la anulabilidad por agente con capacidad de ejercicio restringida y cuyos actos serían anulables).

Si hacemos un corte temporal que se inicia en septiembre del año 2018 (fecha en la que entró en vigencia el Decreto Legislativo $\mathrm{N} .^{\circ} 1384$ ) hasta la fecha en la que este artículo se publica, llegamos a la conclusión de que los contratos que esos más tres millones y medio de peruanos celebraron para satisfacer las necesidades ordinarias de sus vidas, fueron nulos gracias al cambio normativo, porque el artículo 1358 (que los salvaba de esa nulidad) ha sido modificado. Así, se puede afirmar que estamos ante millones de contratos nulos.

Se ha dicho que el Decreto Legislativo $\mathrm{N}$. $^{\circ}$ 1384 era necesario e indispensable para incorporar en la normativa nacional una regulación que proteja a las personas con discapacidad, ya que la normativa original del Código Civil era deficiente.

Sin embargo, me asalta la duda sobre la posibilidad de incorporar una regulación detallada en el Código Civil para la protección de las personas con discapacidad. De hecho, existe una ley y un reglamento de la persona con discapacidad cuyo contenido sí debe ser revisado y actualizado a la realidad en la que hoy vivimos. La tesis que sostengo pasa por tener una regulación de la capacidad legal en el Código Civil (como siempre se tuvo) y una norma en ese mismo cuerpo legal que nos lleve a una regulación específica para la protección de los derechos de las personas con discapacidad. Ello permitirá tener una adecuada y detallada regulación, pues es claro que las personas con discapacidad merecen un trato legal que les permita ejercer sus derechos de manera adecuada y gozar de la protección que su propia situación amerita.

Por otro lado, es cierto que la regulación de la protección de las personas con discapacidad en la normativa original del Código Civil fue deficiente, pero con la actual regulación hoy lo es más. Hemos retrocedido en la materia y ello es innegable. Por ejemplo, se deja en total indefensión a las personas que no teniendo discernimiento pueden verse estafados al celebrar actos jurídicos que hoy son plenamente válidos en virtud de la derogación del inciso 2 del artículo 43 del Código (que establecía que una persona sin discernimiento es incapaz absoluto). Entonces, no se puede afirmar que la regulación que hoy tenemos es mejor y, menos decir que hoy las personas con discapacidad tienen un marco normativo superior al que teníamos antes de septiembre de 2018.

Por otro lado, y ante esta realidad, puedo señalar que casi todas las modificaciones planteadas por el Decreto son defectuosas, y ante tal situación se podría pensar que es posible apelar a una labor de interpretación por parte de los operadores jurídicos. Sin embargo, pongo dos ejemplos en donde 
esa «interpretación» es un imposible ni siquiera en un plano legal, sino lógico:

¿Cómo se interpreta que las personas en estado de coma son ahora consideradas como sujetos de derecho con capacidad restringida (ver inciso 9 del artículo 44)?

¿Cómo se interpreta hoy que un acto jurídico celebrado por una persona sin discernimiento sea plenamente válido?

Existen muchos ejemplos más de estos cambios y téngase en cuenta que lo único que estoy haciendo es transcribir dos casos que saltan a la luz sin mayor esfuerzo. Por lo demás, y si se quiere entrar a una labor interpretativa, yo me pregunto, ¿acaso cabe una interpretación contra legem?

Así las cosas, para este caso en particular, creo que todo esfuerzo interpretativo no hace más que forzar argumentos alambicados para llegar a conclusiones que no ameritan ese esfuerzo, pues la figura de la capacidad debe ser tratada con la simpleza de lo cotidiano. De esta forma, entre entrar al juego de la interpretación de algo que no se entiende y dar una solución que de plano reformule todo, prefiero ir por lo segundo, razón por la cual creo que esta modificación debe anularse. Todo lo demás será como arar en el desierto.

Por otra parte, es importante recordar que el diseño y las finalidades perseguidas por el artículo 1358 se han visto heridos de muerte gracias al Decreto Legislativo $\mathrm{N} .^{\circ} 1384$, sin posibilidad de salvar de la nulidad a todos los actos que son celebrados por personas incapaces con discernimiento. La lectura no puede ser otra.

De otro lado, uno de los temas medulares que debe quedar claro cuando entramos a analizar este asunto es la distinción que existe entre «incapacidad» y «discapacidad». La primera está relacionada a un concepto legal como antítesis del término «capacidad». En cambio, la segunda se refiere a un aspecto biológico-médico. La propia RAE ha definido a la «discapacidad» como la «condición de discapacitado», y al término «discapacitado» como «dicho de una persona: que padece una disminución física, sensorial o psíquica que la incapacita total o parcial- mente para el trabajo o para otras tareas ordinarias de la vida». Si esto es así, la pregunta que surge es ¿en qué momento cuando se habla de discapacidad se debe hacer referencia automática a la incapacidad? La respuesta es clara y se debe entender que por regla general ambos conceptos se desarroIlan y van por cuerdas separadas.

Hace algunos años, cuando comenté una sentencia que apelaba al control difuso y aplicaba la Convención sobre los Derechos de las Personas con Discapacidad, señalé que el contenido de dicha Convención estaba enfocado de manera directa a algunos supuestos que por su propia naturaleza lograban puntos de conexión entre los conceptos de incapacidad y discapacidad, es decir, si bien la regla general es que ambos conceptos no debían confundirse, es claro que por excepción existían algunos casos en donde los dos conceptos encontraban puntos en común que hacía que se tengan que analizar de manera conjunta.

Ante esto, sí debo recalcar que la Convención en modo alguno confunde ambos conceptos, ya que esa equivocación ha nacido en nuestro país, pues se ha legislado y modificado las normas del Código Civil confundiendo términos. Basta ver el texto de los artículos 43 y 44 del Código Civil para entender lo que menciono. Pero lo peor de todo es que nadie quiere asumir la paternidad de esa equivocación, a efectos de poder sentarnos en una mesa y conversar para entender qué ha llevado a ese «legislador» a proponer y materializar esos cambios. Por lo demás, nunca se sometió a consulta ni comentarios el texto del Decreto Legislativo $\mathrm{N}$. 1384 y de ahí que la mayoría de los profesores de Derecho Civil rechacen su contenido.

Así las cosas, se debe dejar claro que, de la lectura de la citada Convención, no se aprecia dónde se exige una «adecuación normativa civil», en los términos que algunos mencionan. Es más, no sé cómo es que se puede llegar a la conclusión de que nuestro sistema poseía una visión paternalista de una institución que, con las falencias que se le reconocen pero que podían ser subsanadas (allí sí) a través de métodos de interpretación para casos concretos, funcionaba para cautelar los derechos 
de, precisamente, las personas que en ciertos casos sufrían de algún tipo de discapacidad.

Para explicar ello, pondré dos ejemplos que bajo el sistema anterior representaban un pleno respeto de los derechos de las personas con discapacidad, tanto positiva como negativamente, en contrapartida con lo que ahora se señala como un sistema paternalista que no respetaba ni cautelaba esos mismos derechos.

Desde que el Código Civil entró en vigencia en 1984, y hasta septiembre del año 2018, era inconcebible señalar que una persona que no caminaba o que tenía alguna extremidad amputada, no podía, por tener tal condición, ejercer sus derechos de manera plena. En este caso, ¿acaso alguien podría haber dicho que a esa persona con discapacidad se le restringía su capacidad de ejercicio? En modo alguno, y esa persona era tan capaz que podía suscribir todos los contratos que deseaba y ejercer todos los derechos como cualquier ciudadano en el país. Entonces, fíjense cómo es que la modificación del Código Civil ha partido de una premisa errónea, pues ha mezclado y confundido los conceptos de incapacidad y discapacidad, sugiriendo que a las personas con discapacidad se les restringían sus derechos por tener tal condición con el antiguo régimen normativo.

Si una persona tenía un deterioro mental que le impedía manifestar su voluntad de manera indubitable o, incluso, si estábamos en presencia de una persona con retardo mental grave, con las normas anteriores a la modificación de septiembre del año 2018, se entendía que dichas personas no podían celebrar contratos y, por la condición en la que se encontraban, era evidente que debían tener un curador para que los represente. Esta solución creada por el sistema salvaguardaba los derechos de estas personas con discapacidad, en vista de que al no tener discernimiento o al no poder expresar una voluntad de manera indubitable, era claro que alguien tenía que asumir esa tarea y la lógica indicaba que tenía que ser un curador, con todas las responsabilidades que el ejercicio de dicho cargo importaba. Entonces, surge aquí la pregunta, ¿cuál es esa carga paternalista al regular estas situaciones de este modo o es que lo que se desea es que esas personas sin discernimiento o que no pueden expresar su voluntad de manera indubitable sean libres para, por ejemplo, contratar, con todos los peligros y riesgos que ello significa? Es claro que se confunden conceptos, pues el ejemplo que cito aquí representa el caso de muchas personas que lograban tener tutela por un sistema diseñado para, efectivamente, salvaguardar sus intereses, y de ninguna forma se le puede confundir con el concepto de paternalismo (o por lo menos no como lo entiende en puridad John Stuart Mill en su ensayo denominado «Sobre la Libertad»). Ello, por la sencilla razón de que existe un fundamento para que el Estado, a través de su legislador, diseñe un modelo de tutela de los derechos de las personas que menciono en mis ejemplos. Así, sí podríamos hablar de un paternalismo en los casos en los que no exista razón para que el Estado intervenga y al hacerlo limite —de manera ilegítima - los derechos de aquellos que sí pueden ejercerlos sin que ese ejercicio represente un peligro para sus propios intereses.

En conclusión, no es cierto que en el antiguo régimen la capacidad se veía limitada por alguna discapacidad, y menos aún lo es que el régimen anterior poseía un tinte paternalista como regla general para regular la institución de la capacidad legal de las personas. En esa línea, no debe utilizarse el contenido de la Convención para justificar las terribles modificaciones que ha sufrido el Código Civil, pues dicho instrumento internacional no confunde incapacidad con discapacidad. Ese error es nuestro y así se debe asumir.

\section{LAS RAZONES PARA AFIRMAR QUE HOY SON NULOS LOS MILLONES DE CONTRA- TOS CELEBRADOS POR INCAPACES CON DISCERNIMIENTO}

Como sabemos, el artículo 219 del Código Civil ha sido modificado en los siguientes términos: 


\begin{tabular}{|l|l|}
\hline \multicolumn{1}{|c|}{ Artículo original } & \multicolumn{1}{c|}{ Artículo vigente } \\
\hline $\begin{array}{l}\text { Artículo 219. El acto jurídico es nulo: } \\
\text { 1. Cuando falta la manifestación de voluntad } \\
\text { del agente. }\end{array}$ & $\begin{array}{l}\text { Artículo 219. El acto jurídico es nulo: } \\
\text { 1. Cuando falta la manifestación de voluntad } \\
\text { del agente. }\end{array}$ \\
$\begin{array}{l}\text { 2. Cuando se haya practicado por persona } \\
\text { absolutamente incapaz, salvo lo dispuesto } \\
\text { en el artículo 1358. }\end{array}$ & $\begin{array}{l}\text { 2. Derogado. } \\
\text { 3. Cuando su objeto es física o jurídicamente } \\
\text { imposible o cuando sea indeterminable. }\end{array}$ \\
$\begin{array}{ll}\text { 3. Cuando su objeto es física o jurídicamente } \\
\text { imposible o cuando sea indeterminable. }\end{array}$ & $\begin{array}{l}\text { 4. Cuando su fin sea ilícito. } \\
\text { 4. Cuando su fin sea ilícito. }\end{array}$ \\
$\begin{array}{l}\text { 5. Cuando adolezca de simulación absoluta. } \\
\text { 6. Cuando no revista la forma prescrita bajo } \\
\text { sanción de nulidad. }\end{array}$ & $\begin{array}{l}\text { 7. Cuando no revista la forma prescrita bajo la ley lo declara nulo. } \\
\text { sanción de nulidad. }\end{array}$ \\
$\begin{array}{l}\text { 7. Cuando la ley lo declara nulo. } \\
\text { 8. En el caso del artículo } \mathrm{V} \text { del Título Preli- } \\
\text { minar, salvo que la ley establezca sanción del artículo V del Título Preli- } \\
\text { diversa. }\end{array}$ & $\begin{array}{l}\text { minar, salvo que la ley establezca sanción } \\
\text { diversa. }\end{array}$ \\
\hline
\end{tabular}

Asimismo, ha sido modificado el artículo 221 del mismo cuerpo normativo, en los siguientes términos:

\begin{tabular}{|c|c|}
\hline Artículo original & Artículo vigente \\
\hline $\begin{array}{l}\text { Artículo 221. El acto jurídico es anulable: } \\
\text { 1. Por incapacidad relativa del agente. } \\
\text { 2. Por vicio resultante de error, dolo, vio- } \\
\text { lencia o intimidación. } \\
\text { 3. Por simulación, cuando el acto real } \\
\text { que lo contiene perjudica el derecho } \\
\text { de tercero. } \\
\text { 4. Cuando la ley lo declara anulable. }\end{array}$ & $\begin{array}{l}\text { Artículo 221. El acto jurídico es anulable: } \\
\text { 1. Por capacidad de ejercicio restringida de } \\
\text { la persona contemplada en los numerales } \\
1 \text { al } 8 \text { del artículo } 44 \text {. } \\
\text { 2. Por vicio resultante de error, dolo, violencia } \\
\text { o intimidación. } \\
\text { 3. Por simulación, cuando el acto real que lo } \\
\text { contiene perjudica el derecho de tercero. } \\
\text { 4. Cuando la ley lo declara anulable. }\end{array}$ \\
\hline
\end{tabular}

Teniendo en cuenta lo indicado, se podría afirmar que por la derogación de las causales de nulidad y de anulabilidad, todos los contratos celebrados por menores de dieciséis años son plenamente válidos, así como también serían válidos todos aquellos contratos celebrados por personas que tienen más de dieciséis y menos de dieciocho años, y los que sufren algún tipo de incapacidad psíquica.

Entiendo que este razonamiento podría esbozarse, sin embargo, la afirmación de que todos los contratos celebrados por menores de dieciséis años son válidos tiene dos grandes y preocupantes aspectos, uno teórico y otro práctico, que constituyen, sin duda alguna, elementos principales de la tesis que expongo.
En primer lugar, y dentro de un plano teórico, no es cierto que esos contratos sean plenamente válidos, pues el artículo 140 del Código Civil, en su texto vigente, establece que para la validez del acto jurídico se requiere plena capacidad de ejercicio, salvo las restricciones establecidas por ley.

A su turno, el artículo 42 indica que toda persona mayor de dieciocho años tiene plena capacidad de ejercicio (con excepción, según esa misma norma, de los mayores de catorce años y menores de dieciocho años que contraigan matrimonio, o quienes ejerciten la paternidad). Es decir, a contrario, es válido decir que toda persona menor de dieciocho años de edad no tiene «plena capacidad de ejercicio». 
Es más, el propio artículo 43, inciso uno, del mismo Código señala que son absolutamente incapaces los menores de dieciséis años, salvo para aquellos actos determinados por la ley.

Así las cosas, no es posible afirmar que los contratos celebrados por menores de dieciséis años son «plenamente válidos» si de una lectura de las normas citadas se aprecia, con claridad, que un agente es capaz desde los dieciocho años en adelante y que para celebrar actos jurídicos la regla general es que, precisamente, el agente tenga «plena capacidad de ejercicio», en los nuevos términos del inciso 1 del artículo 140 del Código Civil.

Además, se olvida la última parte del inciso uno del artículo 43 del Código, pues el mismo hace la salvedad de que no serán absolutamente incapaces los menores de dieciséis para aquellos actos determinados por ley, y es allí donde cobraba vida el contenido del modificado artículo 1358.

Me queda claro que producto de la modificación que ha sufrido el Código Civil se han originado inconsistencias, pero lo que sí no entiendo es cómo ahora se puede afirmar que todos los contratos celebrados por menores de dieciséis años son plenamente válidos.

Pero hay más, porque se podría sostener que, debido a las modificaciones sufridas, no existiría causal para poder declarar la nulidad de millones de contratos, pero esto no es así.

En un artículo publicado en el año 2019, en el N. 59 de la revista Actualidad Civil (con ocasión de emitir su posición sobre la problemática de la disposición de bienes de la sociedad conyugal sin intervención de uno de los cónyuges, y en la que se discute si dicho acto es nulo, anulable o ineficaz), afirmaba un autor lo siguiente: «Dado el estado actual del ordenamiento peruano, la problemática se pone de manifiesto si se considera que la nulidad de dichos actos de disposición se pueden sustentar en la contravención a una norma imperativa de orden público; ya que ello supone que la legislación no ha establecido un remedio diferente al mencionado (que es lo que precisamente sucede en el artículo 315 del CC), configurándose así la residualidad de la nulidad contractual en virtud de lo establecido en el inciso 8 del artículo 219 del Código Civil (el acto jurídico es nulo cuando contraviene una norma de orden público, salvo disposición diferente de la ley). Hablo de residualidad de la nulidad contractual ya que, en el ordenamiento peruano, la contravención a una norma de orden público solo genera la nulidad del contrato si es que una disposición legal específica no ha dispuesto un remedio diferente. Solo en caso dicho remedio específico no exista, el contrato incurrirá en una causal de nulidad propiamente dicha. [...] [P]or lo que en caso de que se considere que el artículo 315 del Código Civil es una norma imperativa de orden público, la nulidad se impondría necesariamente como remedio supletorio [...]» (Campos, 2019, p. 59) (El subrayado es mío).

Así las cosas, siguiendo la tesis expuesta en ese trabajo, se podría afirmar que la vulneración o inobservancia de una norma imperativa de orden público, cuando no existe causal específica que la castigue con nulidad, igual será abrazada por dicha sanción en virtud del artículo V del título preliminar del Código Civil, que establece que son nulos los actos jurídicos cuando contravienen una norma de orden público.

Entonces, la pregunta es si el artículo 140 del Código Civil, que establece como un requisito de validez la presencia de un agente plenamente capaz, es una norma de orden público o no. A mí no me cabe la menor duda de que lo es y pensar lo contrario iría contra toda lógica y conocimiento elemental de la forma cómo funciona nuestro sistema jurídico. De hecho, se ha señalado, con razón, que «el orden público estaría conformado por el conjunto de disposiciones imperativas existentes dentro del sistema jurídico» (Rubio, 2015, p. 107). Nadie podría afirmar que el contenido del artículo 140 del Código Civil no es una norma imperativa, ¿o sí?

En ese sentido, si bien no se tiene una causal expresa que castiga con nulidad a un contrato celebrado por un menor de dieciséis años (pues la causal de agente capaz ha sido derogada del artículo 219), no podemos negar que un contrato celebrado por dicho agente contraviene las normas contenidas en los artículos 140, 42 y 43 del Código, y al ser estas normas de orden público, la causal de nulidad que saltaría a la palestra sería la contenida en el artículo 219, inciso 8, que a su vez nos lleva al artículo V del título preliminar del Código Civil (es nulo el acto jurídico contrario a las leyes que interesan al orden público). 
Entonces, considerando este razonamiento, ¿se podría señalar que esos contratos son «plenamente válidos»? Creo firmemente que no, pero todavía hay más.

Decía al inicio de este punto que son dos los aspectos que resaltar. El primero, de contenido teórico normativo, lo acabo de exponer, y ahora corresponde explicar el aspecto práctico.

Empiezo con una interrogante, inos imaginamos un sistema jurídico y un país en el que se permita a una persona de diez años comprar un bien inmueble, contratar los servicios para realizarse una operación quirúrgica estética, viajar fuera del país sin tener la autorización de sus tutores, contratar para asumir deudas y, en general, celebrar contratos o actos jurídicos sin límite alguno? Yo no lo imagino, pero parece que hay personas que sí lo imaginan, y no solo eso, sino que hay quienes afirman que todo ello es jurídicamente viable hoy en día.

Los problemas prácticos serían inimaginables y los riesgos a los que se podría exponer a esos menores serían verdaderas bombas de tiempo. ¿Eso es lo que queremos? 0 , dicho en otros términos, ¿eso es lo que leemos cuando revisamos las normas contenidas en el Código Civil?

Sinceramente, yo no puedo entender que un contrato celebrado por personas menores de dieciséis años tenga plena validez. Tampoco logro comprender cómo es que la norma del artículo 1358 del Código Civil ha podido ser modificada en términos tan absurdos.

Así las cosas, y con todo el respeto que se merece quienes piensen distinto, sigo pensando que desde la modificación que sufrió el Código Civil en septiembre de 2018 , se han originado en el país millones de nulidades que recaen sobre todos los contratos que menores de dieciséis años con discernimiento han celebrado, siguen celebrando y van a celebrar, pues el artículo 1358 del Código que los salvaba de esa nulidad, hoy ya no existe más.

\section{LA VALIDEZ DE LOS CONTRATOS CELE- BRADOS POR DETERMINADAS PERSONAS CON DISCAPACIDAD}

Una lectura muy básica de la anterior normativa contenida en el Código Civil podría llevar a concluir que los contratos celebrados por personas con diver- sidad psíquica eran considerados, sin más, como nulos, únicamente, por la condición de esas personas.

Lo indicado no se ajusta a la verdad y merece un comentario. Si la premisa de esa afirmación es cierta, no entiendo cómo es posible que se diga que está mal considerar nulo un contrato celebrado por una persona que tiene retardo mental grave. Es decir, ¿acaso no está bien que por ese retardo mental (que es una discapacidad) se señale que dicho sujeto de derecho carece de capacidad legal? Debe tenerse claro que existen casos en donde algunas personas con discapacidad no tienen noción de la realidad, es decir, simplemente no entienden lo que ocurre, de ahí que yo me pregunte si es que es válido pensar que sea a ellos a quienes hoy se les otorgue capacidad plena. Ello me parece un abuso y un mal entendimiento de ese problema.

Entonces, no es que «sin más» se consideraban nulos los contratos celebrados por estas personas, sino que la razón iba más allá, pues lo que se quería era proteger a esa persona con discapacidad (por tener un retardo mental grave) para que alguien no se pueda aprovechar de ella y se otorgaba un resguardo a través de la figura de los curadores para que sean ellos quienes puedan contratar en nombre de esas personas y, de esta manera, beneficiarlas y cuidarlas. Así, yo me pregunto: ¿qué tiene de malo que el Estado cuide y tutele los derechos e intereses de este grupo de personas, castigando con nulidad a los contratos que celebren? La respuesta es que nada tiene de malo. Es más, en un sistema donde lo que se busca es proteger al más débil, una política normativa como esa coadyuvaba a lograr tal fin.

Ahora bien, no puedo dejar de reconocer que es cierto que la antigua regulación incluía en un solo supuesto a una variedad de casos que no merecían, necesariamente, el mismo tratamiento. En efecto, si en el párrafo anterior he puesto como ejemplo el caso de una persona con retardo mental grave -a quien, por obvias razones, se le consideraba sin capacidad legal para celebrar actos-, podría poner en este párrafo el caso de una persona con retardo mental leve a quien, qué duda cabe, no debería limitársele la capacidad de ejercicio de sus derechos. Esto es evidente, pues pensar lo contrario sería aceptar un caso de discriminación hacia esta persona por el solo hecho de tener esa discapacidad. 
Entonces, para diferenciar estos casos (los graves, los moderados y los leves), la antigua regulación tenía en la figura del «discernimiento» a la piedra de toque que iba a determinar si estábamos ante un caso de incapacidad absoluta, incapacidad relativa o capacidad plena. De esta forma, con ese régimen, y teniendo las posibilidades que sus normas otorgaban, sí era posible entrar a esa distinción, pues el juez, en el caso concreto, podía señalar si es que una persona era interdicta y tenía la potestad de limitarle la capacidad de ejercicio. En ese escenario, el acervo probatorio iba a ser fundamental para que el juez interprete la norma y emita su sentencia. Sin embargo, hoy los jueces se ven atados de manos, porque ocurre que en algunos casos no tienen claridad para saber cómo proceder, gracias a lo inorgánico y confuso que resultan los nuevos textos de diversas normas del Código Civil.

Entonces, se confunde y no se interpreta las normas que han sido modificadas por el terrible Decreto Legislativo $\mathrm{N} .{ }^{\circ} 1384$, con la gravedad de que hoy, las normas vigentes, no permiten una interpretación distinta a la de sus propios textos.

\section{ALGUNAS PRECISIONES FINALES}

Me queda claro que hoy todos los contratos celebrados por menores de dieciséis años son nulos en aplicación del inciso 8 del artículo 219 del Código Civil que, a su vez, nos lleva a la aplicación del artículo $\mathrm{V}$ del título preliminar de dicho Código. Debe quedar claro que las personas menores de dieciséis años son incapaces absolutos y, para ello, basta revisar el inciso 1 del artículo 43 in fine.

El Derecho tiene que estar al alcance del ciudadano y, sin la necesidad de ser un reglamento, debe intentar regular de la manera más clara posible todas las instituciones jurídicas. De ahí que sea necesario dar un paso atrás para volver a estudiar, analizar y proponer un sistema serio que recoja los lineamientos de la CDPD y, sobre todo, que sea útil y no genere, como hoy, interpretaciones forzadas, lagunas, vacíos e indefensión en esas personas que son su razón de ser.

Asimismo, debemos volver a la versión original del artículo 1358 del Código Civil, pues esa regla reconocía una realidad y servía para no tener millones de contratos nulos.
Cabe anotar que, en todo este análisis, nada tiene que ver el aspecto ideológico, sino que simplemente existen casos en los que los actos que celebra una persona con discapacidad deben tener consecuencias o limitaciones establecidas así por la ley. Eso es así en un sistema paternalista o en un sistema que tenga cualquier otra característica.

De otra parte, se podría pensar que se deben dirigir los esfuerzos de la doctrina para generar criterios interpretativos que ayuden a la solución de casos, ello mientras se espera y promueve la modificación de las normas del Código Civil. Yo entiendo estas buenas intenciones, pero sinceramente creo que es una pérdida de recursos el entrar a un juego creativo de criterios de interpretación sobre la base de un conjunto de normas defectuosas y que no tienen ningún sentido ni organicidad. Así, en lugar de entrar a ese juego y esperar y promover una modificación, prefiero trabajar en lo segundo y dar todos mis esfuerzos y el tiempo en llamar la atención para entender que las normas han sido terriblemente modificadas. «El que mucho abarca poco aprieta», y yo prefiero seguir en esta tarea de explicar las inconsistencias del Decreto Legislativo N. 1384 (solicitando su derogación), pues creo que nada bueno aporta al respeto de los derechos de las personas con discapacidad y hace un tremendo daño a la sociedad y al sistema jurídico en su conjunto.

Al final, la Academia debe originar espacios en donde se intercambien pensamientos, siempre de manera alturada, y con el respeto y aprecio que sus integrantes se deben tener. Es en ese espacio en el que planteo esta posición.

\section{UNA PROPUESTA REALISTA}

El jueves 2 de mayo de 2019 participé en un Seminario organizado por el Centro de Investigaciones Judiciales del Poder Judicial, que se llevó a cabo en la Corte Suprema de Justicia de la República. En dicha oportunidad expuse mis ideas sobre el nuevo régimen de la capacidad en el Código Civil, a partir de la entrada en vigencia de las normas modificadas el año 2018.

Al final de mi intervención expliqué lo que creo que debería ocurrir si es que queremos enmendar el error que se ha cometido al modificar de manera tan irreflexiva nuestro Código Civil. 
Mi propuesta fue que se emita una norma que tenga dos finalidades:

Que derogue todo el texto del Decreto Legislativo N. ${ }^{\circ} 1384$.

Que establezca de manera expresa que vuelven a entrar en vigencia el texto de las normas modificadas por ese Decreto Legislativo, a efectos de que no sea aplicable el principio por el que «por la derogación de una ley no recobran vigencia las que ella hubiere derogado», contenido en el artículo I del título preliminar del Código Civil.

De esta forma, daríamos un paso atrás que, contra lo que se pueda creer, sería beneficioso, ya que solo así podríamos remediar el daño que se ha causado a la sociedad con esa modificación.

Sin embargo, el asunto no debería quedar allí, pues soy plenamente consciente de que las finalidades que persigue la Convención sobre los derechos de las personas con discapacidad deben encontrar materialización en el ordenamiento jurídico peruano, razón por la cual también propuse que se trabaje en una Comisión los artículos que se deberían modificar e incluir en nuestro Código Civil para otorgar un tratamiento normativo para las figuras de los apoyos y salvaguardas, y eliminar, en todo lo que se considere, cualquier supuesto discriminatorio contra las personas con discapacidad. Dicha Comisión debería estar conformada por diversos actores, entre los que se encuentren, principalmente, los propios jueces, notarios, profesores de Derecho Civil y actores de la sociedad civil que tengan vinculación directa con el cuidado y protección de los derechos de las personas con discapacidad. Se debe procurar un debate a puertas abiertas y no solo en cuatro paredes.

De esta forma, el objetivo es buscar un equilibrio entre la protección del pleno ejercicio de los derechos de las personas con discapacidad y la tutela de los derechos de estas personas, ya que es claro que con la actual regulación de, por ejemplo, la capacidad legal, se deja en total desprotección a muchas personas con discapacidad.

Finalmente, invoqué el contenido del artículo $X$ del título preliminar del Código Civil, el mismo que establece lo siguiente:

Artículo X. «La Corte Suprema de Justicia, el Tribunal de Garantías Constitucionales y el Fiscal de la Nación están obligados a dar cuenta al Congreso de los vacíos o defectos de la legislación.

Tienen la misma obligación los jueces y fiscales respecto de sus correspondientes superiores».

Ello debido a que el trabajo de la Comisión que propongo que sea creada, bien podría ser enviado por la Corte Suprema al Congreso, pues resulta claro que estamos ante una serie de defectos y vacíos que posee el Código Civil.

\section{REFERENCIAS BIBLIOGRÁFICAS}

Arias-Schreiber, P.; Cárdenas Quirós, C. y AriasSchreiber, M. Á. (2015). Contratos Parte General. En E. D. (compiladora). Código Civil. Exposición de Motivos y Comentarios. 2.a ed. Tomo VI. Lima: Thomsom Reuters.

Campos García, H. (2019). La compraventa de un bien social por uno de los cónyuges y el (pendiente) VIII Pleno Casatorio: ¿es preferible la tesis "Proineficacia" frente a la tesis de la "pronulidad"? Actualidad Civil, número 59.

(s.f.). Alegato a favor de la validez de "millones" de contratos. Breves anotaciones a la modificación del artículo 1358 CC por el Decreto Legislativo 1384. Recuperado de https://legis.pe/alegato-favor-validez-millonescontratos-breves-anotaciones-modificacionarticulo-1358-c-c-decreto-legislativo-1384 / Instituto Nacional de Estadística e Informática. (2018). Censo Nacional 2017. Tomo III. Lima.

Rubio Correa, M. (2015). El Título Preliminar del Código Civil. 11.a ed. Lima: Fondo Editorial de la PUCP. 